(C) The Authors 2012

\title{
Dietary dry bean effects on hepatic expression of stress and toxicity-related genes in rats
}

\author{
Erica L. Daniell ${ }^{1,2}$, Elizabeth P. Ryan ${ }^{2,3}$, Mark A. Brick ${ }^{4}$ and Henry J. Thompson ${ }^{1 *}$ \\ ${ }^{1}$ Cancer Prevention Laboratory, Colorado State University, 1173 Campus Delivery, Fort Collins, CO 80523, USA \\ ${ }^{2}$ Department of Food Science and Human Nutrition, Colorado State University, Fort Collins, CO 80523, USA \\ ${ }^{3}$ Department of Clinical Sciences, Colorado State University, Fort Collins, CO 80523, USA \\ ${ }^{4}$ Department of Soil and Crop Science, Colorado State University, Fort Collins, CO 80523, USA
}

(Submitted 27 July 2011 - Final revision received 5 October 2011 - Accepted 6 October 2011)

\section{Abstract}

Dry bean (Phaseolus vulgaris L.) consumption is associated with reduced risk for a number of chronic diseases. In westernised societies, dry bean consumption is particularly low (approximately $2-4 \mathrm{~kg} /$ capita per year) and little information is available about the safety of increasing dietary intake in humans to achieve levels that prevent and control chronic diseases. In anticipation of a human intervention study to address the safety and efficacy of increasing bean consumption, a dose-response study with dietary beans was conducted to establish whether increased bean consumption in rats exhibits changes indicative of hepatic stress or toxicity. Transcript levels from a panel of stress and toxicity-related genes were analysed in female Sprague-Dawley rats fed a dose range of dietary beans that bracketed amounts relevant to human consumption globally. Cooked red bean was incorporated into a purified diet formulation at $0,7 \cdot 5,15,30$ or $60 \% \mathrm{w} / \mathrm{w}$ for the assessment of adaptive patterns of gene expression using quantitative PCR array. Of the eighty-four genes evaluated, the expressions of Cyp3a11, Cyp7a1, Fmo1, Gstm1, Mif and Ugt1a6 were elevated, whereas the expression of Hspa8 was down-regulated. Liver gene expression was not modulated in a manner indicative of an adverse response. Only the expression of the cholesterol $7 \alpha$ hydoxylase and UDP-glucuronosyltransferase genes increased in a dose-dependent manner at nutritionally relevant dietary bean concentrations. These candidate genes may contribute to the health benefits attributed to increased bean consumption.

Key words: Dry beans (Phaseolus vulgaris L.): Gene expression: Toxicity/stress response: Liver: Rats

Dry beans (Phaseolus vulgaris L.) are a widely available and affordable staple food crop. Worldwide consumption varies considerably, ranging from 2 to $3.5 \mathrm{~kg} /$ capita per year in Europe and the United States to as high as $40 \mathrm{~kg} / \mathrm{capita}$ per year in Burundi ${ }^{(1,2)}$. Numerous health benefits have been associated with the regular consumption of dry bean, and emerging evidence supports a relationship between dry bean consumption and chronic disease prevention ${ }^{(3,4)}$. Given the dramatic and continued rise in chronic disease incidence and prevalence globally, there is potential for increased bean consumption as a component of an international effort to reverse the impact of chronic diseases in all sectors of the population $^{(5)}$.

Dry bean consumption has been linked to reductions in the occurrence of a number of chronic diseases including type 2 diabetes, CVD and cancer. Elevated total cholesterol and LDL-cholesterol are associated with CHD risk, and multiple studies have reported that dietary dry bean interventions involving consumption of approximately $92 \mathrm{~g}$ cooked dry bean/d for at least 3 weeks resulted in significantly reduced serum cholesterol levels ${ }^{(6-8)}$. In a Latin American population, consumption of approximately 79-92 g of cooked dry beans/d was associated with a $38 \%$ lower risk of myocardial infarction compared with non-consumption ${ }^{(9)}$. Prospective cohort studies have also found a significant correlation between dry bean consumption and reduced risk for the development of colon and breast cancer ${ }^{(10-12)}$. The Polyp Prevention Trial examined the effect of a high fruit and vegetable diet intervention on the recurrence of adenomatous polyps in the large bowel, and found that individuals who increased their consumption of legumes (including dry bean and lentils) experienced a significantly reduced risk for advanced adenoma recurrence $(\mathrm{OR}=0 \cdot 35)^{(11)}$. The Nurses Health Study II revealed an effect of pulse consumption on breast cancer risk, with a significant inverse association between consumption of at least two servings of dry beans per week (approximately 160-180 g/week) and breast cancer (relative risk $=0.76)^{(10)}$.

\footnotetext{
Abbreviations: $C_{t}$, cycle threshold; UGT, UDP-glucuronosyltransferase.
}

*Corresponding author: H. J. Thompson, fax +1970 491 3542, email henry.thompson@colostate.edu 
Edible dry beans are an excellent source of dietary protein, resistant starch and fibre, are low in fat and are a good source of $\mathrm{B}$ vitamins and numerous mineral nutrients ${ }^{(3,4)}$. In addition to being a rich source of nutrients, beans contain a broad array of non-nutrient bioactive substances many of which have been reported to exert either beneficial or potentially harmful effects on human health $^{(13-16)}$. Of particular interest to the work reported herein, some of the phytochemicals found in bean seeds are synthesised as natural defence mechanisms against insects or bacterial and mould infestations, and have the potential to elicit toxic effects when consumed 'uncooked' by mammals ${ }^{(13,15)}$. Multiple anti-nutritive molecules occur in dry beans, including amylase inhibitors, trypsin inhibitors and the lectin protein phytohaemagglutinin ${ }^{(17,18)}$. Phytohaemagglutinin is a major concern for uncooked bean intake, as it has demonstrated toxic effects such as gastroenteritis, nausea and diarrhoea in mammals and humans ${ }^{(19)}$. There is also some question as to whether phytohaemagglutinin plays a role in the aetiology of immune-based chronic diseases such as type 2 diabetes and rheumatoid arthritis ${ }^{(18)}$. However, these anti-nutritive factors are rendered harmless by proper cooking $^{(20)}$.

Rodent models are commonly used in the evaluation of the safety and efficacy of dietary factors. In the present study, rats were fed a range of dietary concentrations of cooked bean that bracketed amounts relevant to human consumption globally (Table 1 ). The hypothesis evaluated was that increasing bean intake does not elicit adaptive changes in gene expression that are indicative of hepatic stress and toxicity. Based on a recent report that the magnitude of altered gene expression and the number of genes affected in the liver were greater using a short- rather than long-term feeding design, the study hypothesis was tested using a $7 \mathrm{~d}$ dietary exposure model ${ }^{(21)}$.

\section{Experimental methods}

\section{Animals}

Weanling female Sprague-Dawley rats ( $n$ 42) were obtained from Taconic Farms and housed in the institutional vivarium. Room temperature was maintained at $25^{\circ} \mathrm{C}$ with $30 \%$ relative humidity and a $12 \mathrm{~h}$ light $-12 \mathrm{~h}$ dark cycle. Animals were fed AIN-93-G powdered diet ${ }^{(22)}$ until $27 \mathrm{~d}$ of age, followed by feeding of the experimental diets from 27 to $34 \mathrm{~d}$ of age.

Table 1. Rat bean diet comparison to human consumption

\begin{tabular}{lccc}
\hline $\begin{array}{l}\text { Mass of bean } \\
\text { powder }(\mathrm{g} / 100 \mathrm{~g} \\
\text { total rat diet) }\end{array}$ & $\begin{array}{c}\text { Approximate } \\
\text { human } \\
\text { equivalent }(\mathrm{g} / \mathrm{d})^{\star}\end{array}$ & $\begin{array}{c}\text { Human } \\
\text { equivalent } \\
(\mathrm{kJ} / \mathrm{d})^{*}\end{array}$ & $\begin{array}{c}\text { Human } \\
\text { equivalent: } \\
\% \text { of a } \\
8368 \mathrm{~kJ} \text { diet }\end{array}$ \\
\hline 0 & 0 & 0 & 0 \\
7.5 & 138 & $690 \cdot 36$ & 8.25 \\
15 & 276 & $1380 \cdot 72$ & 16.5 \\
30 & 552 & 2761.44 & 33 \\
60 & 1,104 & 5522.88 & 66 \\
\hline
\end{tabular}

* Based on assumption of $920.48 \mathrm{~kJ}$ per average serving of beans.
Rats were randomly assigned to five groups that contained: $0 \%(n 18), 7 \cdot 5 \%(n 6), 15 \%(n 6), 30 \%(n 6)$ or $60 \%(n 6)$ $\mathrm{w} / \mathrm{w}$ red bean incorporated into a modification of AIN93G diet as previously described ${ }^{(23)}$. Animals were housed three per cage and had ad libitum access to food and water at all times during the study. The animals were weighed at the time of randomisation and at study termination. The Colorado State University Animal Care and Use Committee-approved protocols were used for animal research.

\section{Experimental diets}

The experimental diets were a modification of AIN-93-G diet, and were identical in composition to those previously described for inhibition of mammary carcinogenesis ${ }^{(23)}$. Dry red bean was provided by Archer Daniels Midland Company and sent to Bush Brothers \& Company for canning. Raw beans were packed in standard brine without additives and then cooked and canned according to commercial standard. The fully processed, canned beans were sent to Van Drunen Farms where they were drained, freeze-dried and milled into a homogeneous powder. The bean powder was stored at $-20^{\circ} \mathrm{C}$ until incorporated into rodent diets. Diets were formulated using specific guidelines ${ }^{(22)}$ and adjusted to have the same percentage of crude protein, fat and carbohydrate using the proximate analysis of the red bean powder (Warren Analytical). Ground cooked red bean powder was added to AIN93G for a final 7.5, 15, 30 or $60 \% \mathrm{w} / \mathrm{w}$ concentration. Differences in macronutrient composition were balanced with purified diet components. Casein and maizestarch were adjusted to maintain similar macronutrient content across red bean dosage groups. The control diet contained $7.5 \%$ crude fibre to be consistent with experimental dry bean diets. The percentage of dry beans incorporated into the diets is expressed as mass of bean powder in $\mathrm{g} / 100 \mathrm{~g}$ of total diet ${ }^{(23)}$.

\section{Study design}

Young, rapidly growing rats were used because of sensitivity to detecting adverse effects of dietary agents. Adaptive changes in gene expression were assessed after short-term feeding for $7 \mathrm{~d}$. Commercially cooked and canned bean was used to eliminate potential confounding of results by dry bean components that may be toxic in raw beans or when dry beans are not properly cooked. The absence of phytohaemagglutinin activity was confirmed in the red bean powder that was evaluated (data not shown). The small red bean market class was assessed since this market class has been reported to have a very high concentration of bioactive phenolic compounds with antioxidant activity ${ }^{(24)}$. The dose range of beans studied brackets the range of reported dry bean intake in various populations worldwide ${ }^{(1)}$.

\section{Necropsy}

Rats were stratified across control and experimental groups for necropsy. Necropsy occurred when the rats were $34 \mathrm{~d}$ of 
age and had received the experimental diets for $7 \mathrm{~d}$. Nonfasted animals were euthanised via inhalation of gaseous $\mathrm{CO}_{2}$ followed by cervical dislocation. The livers were removed immediately after plasma collection, freeze-clamped, snapfrozen in liquid $\mathrm{N}_{2}$ and stored at $-80^{\circ} \mathrm{C}$.

\section{RNA isolation}

Total RNA was isolated from the liver using the RNeasy Mini RNA isolation kit (Qiagen) according to the manufacturer's protocol. RNA yield was determined using a Nanodrop spectrophotometer (Thermo Fisher Scientific) and integrity was assessed using the Experion automated microfluidic capillary electrophoresis system (Bio-Rad).

\section{Gene expression analysis}

Gene expression analysis was performed using the $\mathrm{RT}^{2}$ Profiler PCR Array: Rat Stress and Toxicity Pathway Finder (SuperArray) (a complete list of included primer sets can be found at: http://www.sabiosciences.com/rt_pcr_product/ HTML/PARN-003A.html). For the analysis, $500 \mathrm{ng}$ of purified RNA sample was used according to the manufacturer's protocol. The following quantitative PCR conditions were applied on the iCycler thermal cycler (Bio-Rad): initial denaturation step at $95^{\circ} \mathrm{C}$ for $10 \mathrm{~min}$ followed by forty cycles of $95^{\circ} \mathrm{C}$ for $15 \mathrm{~s}$, and then of $60^{\circ} \mathrm{C}$ for $1 \mathrm{~min}$. Cycle threshold $\left(C_{t}\right)$ values were obtained using the iCycler software (Bio$\mathrm{Rad})$. The $C_{t}$ values were averaged from five housekeeping genes (acidic ribosomal protein P1 (Rplp1), hypoxanthineguanine phosphoribosyltransferase (Hprt), ribosomal protein L13a (Rpl13A), lactate dehydrogenase A (Ldha) and betaactin $(A c t b))$ for normalisation purposes. Fold change values for gene expression were determined using the SuperArray online $\mathrm{RT}^{2}$ Profiler PCR data analysis software comparing all treatments to control $\left(0 \%\right.$ red bean) using the $2^{-\Delta \Delta C_{t}}$ method $^{(25)}$.

\section{Statistical analysis}

Data were analysed using SAS 9.1 (SAS Institute, Inc.); and two-way ANOVA was performed on adjusted $C_{t}$ values and weight gain to determine the statistical significance of increasing red bean dose. Because eighty-four genes were simultaneously investigated, the Benjamini-Hochberg multiple testing adjustment for false discovery rate was performed ${ }^{(26)}$. Gene expression changes with a $P$-value $<0.05$ were determined to be significantly affected by beans consumption. Subsequently, Dunnett's test for post hoc analysis was performed for all genes that were found to be significantly affected by bean dose in order to determine which bean doses $(7 \cdot 5,15$, $30,60 \%)$ were significantly different from the control ( $0 \%)$.

\section{Results}

Body weight was measured at the time of randomisation and at the end of the study. As shown in Fig. 1, no differences in growth rate were observed among diet groups. Controlling

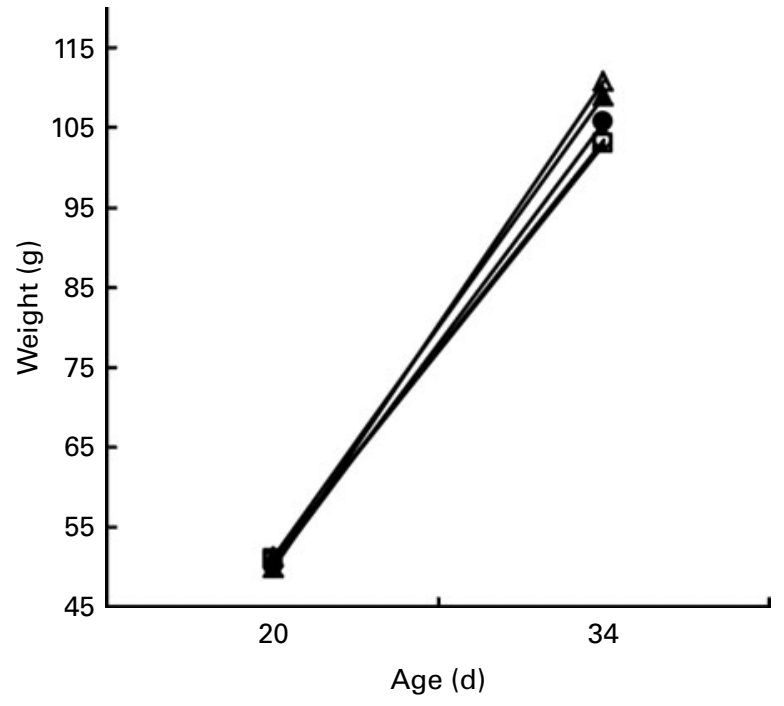

Fig. 1. Body weight gain over time among dietary treatment groups. Animals were weighed on 20 and $34 \mathrm{~d}$ of age. No significant differences in body weight were observed among dietary treatment groups. $-0,0 \%$; - , $7.5 \% ; \unlhd, 15 \% ; \neg, 30 \% ; \square, 60 \%$.

the false discovery rate at $5 \%$ for multiple testing across genes, the expression of eight genes of the eighty-four examined was significantly different after consumption of red bean diet compared to control $(0 \% \mathrm{w} / \mathrm{w}$ beans). The eighty-four genes in the array that were investigated for bean consumption effects are listed in Table 2 with their associated $P$-value. The expressions of the following genes: cyclin G1 (Ccng1), cytochrome p450 3a11 (Cyp3a11), cytochrome p450 7a1 (Cyp7a1), flavin containing mono-oxygenase (Fmo1), glutathione-S-transferase (Gstm1), heat shock protein 8 (Hspa8), macrophage migration inhibitory factor (Mif) and UDP glucuronosyltransferease 1 family, polypeptide A6 (Ugt1aG) were significantly changed by bean in the diet (Table 2). Increased expression of Cyp3a11, Fmo1, Gstm1 and Mif was detected at the highest dietary concentration of dry bean, whereas Cong1 and Hspas expressions were down-regulated compared to the control group (Fig. 2). The results presented herein are consistent with the absence of acute liver stress or toxicity responses even in rats fed as much as $60 \% \mathrm{w} / \mathrm{w}$ beans in the diet. Expression of Cyp $7 a 1$ and Ugt1a6 increased progressively with increasing dietary concentration of bean (Fig. 3). These genes are recognised for induction following exposure to xenobiotics; additionally, activity of these genes has been associated with health benefits as will be discussed next.

\section{Discussion}

A classical first-step approach to assessing the safety of foods in humans and animals has centred on calculating an apparent digestibility following dietary intake, with limited attention on dose-dependent differences ${ }^{(27-30)}$. The digestibility and nutritional properties of whole cooked beans (Phaseolus vulgaris L. $)^{(31-35)}$ have been reported and illustrates the complex interactions that can occur among protein digestibility, bean phytochemicals and potential anti-nutrients. The effect 
Table 2. Genes analysed for changes by bean diets using the $\mathrm{RT}^{2}$ Profiler PCR Array: Rat Stress and Toxicity Pathway Finder

\begin{tabular}{|c|c|c|c|c|}
\hline Gene symbol & Gene name & Entrez ID & $P$ & FDR \\
\hline Anxa5 & Annexin A5 & 25673 & 0.176 & 0.584 \\
\hline Atm & Ataxia telangiectasia mutated homologue & 300711 & 0.535 & 0.871 \\
\hline Bax & Bcl2-associated X protein & 24887 & 0.071 & 0.420 \\
\hline $\mathrm{Bcl} 2 / 1$ & Bcl2-like 1 & 24888 & 0.066 & 0.420 \\
\hline Casp1 & Caspase 1 & 25166 & 0.072 & 0.420 \\
\hline Casp8 & Caspase 8 & 64044 & 0.170 & 0.579 \\
\hline Ccl21b & Chemokine ( $\mathrm{C}-\mathrm{C}$ motif) ligand $21 \mathrm{~b}$ & 298006 & 0.377 & 0.778 \\
\hline $\mathrm{Ccl3}$ & Chemokine ( $\mathrm{C}-\mathrm{C}$ motif) ligand 3 & 25542 & $0 \cdot 107$ & 0.492 \\
\hline Ccl4 & Chemokine ( $\mathrm{C}-\mathrm{C}$ motif) ligand 4 & 116637 & 0.042 & 0.341 \\
\hline Cenc & Cyclin C & 114839 & 0.015 & 0.205 \\
\hline Ccnd1 & Cyclin D1 & 58919 & 0.071 & 0.420 \\
\hline Ccng $1^{\star}$ & Cyclin G1 & 25405 & 0.002 & 0.042 \\
\hline Cdkn1a & Cyclin-dependent kinase inhibitor $1 \mathrm{~A}$ & 114851 & 0.017 & 0.205 \\
\hline Chek2 & CHK2 checkpoint homologue & 114212 & 0.052 & 0.386 \\
\hline Cryab & Crystallin, $\alpha \mathrm{B}$ & 25420 & 0.454 & 0.837 \\
\hline Csf2 & Colony-stimulating factor 2 & 116630 & $0 \cdot 190$ & 0.606 \\
\hline Cxcl10 & Chemokine ( $\mathrm{C}-\mathrm{X}-\mathrm{C}$ motif) ligand 10 & 245920 & 0.044 & 0.348 \\
\hline Cyp1a1 & Cytochrome p450 1a1 & 24296 & 0.295 & 0.714 \\
\hline Cyp1b1 & Cytochrome p450 1b1 & 25426 & 0.235 & 0.641 \\
\hline Сур2аза & Cytochrome p450 2a3a & 24299 & 0.397 & 0.800 \\
\hline Cyp2b15 & Cytochrome p450 2b15 & 29295 & 0.738 & 0.933 \\
\hline Cyp2b3 & Cytochrome p450 2b3 & 286953 & 0.734 & 0.933 \\
\hline Сур2c13 & Cytochrome p450 2c13 & 171521 & 0.310 & 0.727 \\
\hline Сур3а11* & Cytochrome p450 3a11 & 266682 & 0.001 & 0.028 \\
\hline Cyp4a14 & Cytochrome p450 4a14 & 298423 & 0.332 & 0.727 \\
\hline Cур4а22 & Cytochrome p450 4a22 & 170544 & 0.690 & 0.927 \\
\hline Cyp7a1* & Cytochrome p450 7a1 & 25428 & 0.000 & $<0.001$ \\
\hline Ddit3 & DNA-damage inducible transcript 3 & 29467 & 0.403 & 0.802 \\
\hline Dnaja1 & DnaJ (Hsp40) homologue A1 & 65028 & 0.018 & 0.205 \\
\hline E2f1 & E2F transcription factor 1 & 399489 & 0.035 & 0.312 \\
\hline Egr1 & Early growth response 1 & 24330 & 0.607 & 0.891 \\
\hline Ephx2 & Epoxide hydrolase 2 , cytoplasmic & 65030 & 0.543 & 0.871 \\
\hline Ercc1 & Excision repair cross-complementing rodent repair deficiency, complementation group 1 & 292673 & 0.592 & 0.891 \\
\hline Ercc2 & Excision repair cross-complementing rodent repair deficiency, complementation group 2 & 308415 & 0.500 & 0.871 \\
\hline Ercc4 & Excision repair cross-complementing rodent repair deficiency, complementation group 4 & 304719 & 0.696 & 0.871 \\
\hline Faslg & Fas ligand (TNF superfamily, member 6 ) & 25385 & 0.001 & 0.928 \\
\hline $\mathrm{Fmo1}^{*}$ & Flavin containing mono-oxygenase 1 & 25256 & 0.243 & 0.023 \\
\hline Fmo4 & Flavin containing mono-oxygenase 4 & 246247 & 0.067 & 0.652 \\
\hline Fmo5 & Flavin containing mono-oxygenase 5 & 246248 & 0.980 & 0.420 \\
\hline Gadd45a & Growth arrest and DNA-damage-inducible, $45 \alpha$ & 25112 & $0 \cdot 151$ & 0.998 \\
\hline Gpx1 & Glutathione peroxidase 1 & 24404 & 0.016 & 0.545 \\
\hline Gpx2 & Glutathione peroxidase 2 & 29326 & 0.020 & 0.205 \\
\hline Gsr & Glutathione reductase & 116686 & $<.0001$ & 0.205 \\
\hline Gstm1* & Glutathione $S$-transferase, mu 1 & 24423 & 0.074 & 0.004 \\
\hline Gstm3 & Glutathione $S$-transferase, mu 3 & 57298 & 0.942 & 0.420 \\
\hline Hmox1 & Haeme oxygenase (decycling) 1 & 24451 & 0.607 & 0.997 \\
\hline Hmox2 & Haeme oxygenase (decycling) 2 & 79239 & 0.466 & 0.891 \\
\hline Hsf1 & Heat shock transcription factor 1 & 79245 & $0 \cdot 170$ & 0.839 \\
\hline Hsph1 & Heat shock $105 \mathrm{kDa} / 110 \mathrm{kDa}$ protein 1 & 288444 & 0.601 & 0.620 \\
\hline Hspa1a & Heat shock $70 \mathrm{kDa}$ protein $1 \mathrm{~A}$ & 24472 & 0.572 & 0.579 \\
\hline Hspa1I & Heat shock protein 1 -like & 24963 & 0.019 & 0.891 \\
\hline Hspa4 & Heat shock protein 4 & 266759 & 0.002 & 0.879 \\
\hline Hspa5 & Heat shock $70 \mathrm{kDa}$ protein 5 & 25617 & 0.328 & 0.205 \\
\hline Hspa8* & Heat shock protein 8 & 24468 & 0.557 & 0.044 \\
\hline Hspb1 & Heat shock 27 kDa protein 1 & 24471 & 0.465 & 0.727 \\
\hline Hspd1 & Heat shock protein 1 (chaperonin) & 63868 & 0.209 & 0.871 \\
\hline Hspe1 & Heat shock $10 \mathrm{kDa}$ protein 1 (chaperonin 10 ) & 25462 & 0.189 & 0.839 \\
\hline lgfbp6 & Insulin-like growth factor binding protein 6 & 25641 & 0.744 & 0.606 \\
\hline $1 / 1 a$ & $\mathrm{IL} 1 \alpha$ & 24493 & 0.425 & 0.835 \\
\hline $1 / 1 b$ & IL1 $\beta$ & 24494 & 0.020 & 0.205 \\
\hline 116 & IL6 & 24498 & 0.544 & 0.871 \\
\hline //18 & IL18 & 29197 & 0.730 & 0.933 \\
\hline Lta & Lymphotoxin A & 25008 & 0.094 & 0.933 \\
\hline Mdm2 & p53 binding protein homologue & 314856 & 0.001 & 0.456 \\
\hline$M_{i f *}^{*}$ & Macrophage migration inhibitory factor & 81683 & 0.555 & 0.028 \\
\hline Nfkb1 & Nuclear factor of kappa light polypeptide gene enhancer in B-cells 1 & 81736 & 0.817 & 0.871 \\
\hline Nfkbia & Nuclear factor of kappa light polypeptide gene enhancer in B-cells inhibitor, $\alpha$ & 25493 & 0.346 & 0.969 \\
\hline Nos2 & Nitric oxide synthase 2 , inducible & 24599 & 0.757 & 0.733 \\
\hline Pcna & Proliferating cell nuclear antigen & 25737 & 0.042 & 0.938 \\
\hline
\end{tabular}


Table 2. Continued

\begin{tabular}{llrr}
\hline Gene symbol & Gene name & Entrez ID & $P$ \\
\hline Por & P450 (cytochrome) oxidoreductase & 29441 & 0.113 \\
Rad23a & RAD23 homologue A & 361381 & 0.435 \\
Rad50 & RAD50 homologue & 64012 & 0.519 \\
Serpine1 & Serine (or cysteine) peptidase inhibitor, clade E, member 1 & 0.341 \\
Sod1 & Superoxide dismutase 1 & 24617 \\
Sod2 & Superoxide dismutase 2, mitochondrial & 0.544 \\
Tnfrsf1a & TNF receptor superfamily, member 1a & 24786 & 0.455 \\
Tnfsf10 & TNF (ligand) superfamily, member 10 & 24787 & 0.139 \\
Tp53 & Tumour protein p53 & 25625 & 0.738 \\
Tradd & TNFRSF1A-associated via death domain & 246775 & 0.727 \\
Ugt1a6 & UDP glucuronosyltransferase 1 family, polypeptide A6 & 24842 & 0.933 \\
Ung & Uracil-DNA glycosylase & 0.933 \\
Xrcc1 & X-ray repair complementing defective repair in Chinese hamster cells 1 & 0.927 \\
Xrcc2 & X-ray repair complementing defective repair in Chinese hamster cells 2 & 0.492 \\
Xrcc4 & X-ray repair complementing defective repair in Chinese hamster cells 4 & 0.107 \\
\end{tabular}

FDR, false discovery rate; Entrez ID, Entrez gene identifier.

* Genes considered to be significantly affected by bean dose.

of bean consumption on increased nitrogen excretion in rats, however, did not seem to affect the biological value of the protein when compared to casein or uncooked beans ${ }^{(36)}$. A more recent study employed a short- and long-term experimental feeding study design in rats with dietary wheat flour and assessed the potential for adverse health effects via changes in liver gene expression using a DNA microarray ${ }^{(21)}$. This study reported that short-term feeding significantly modulated more genes and the magnitude of liver gene expression when compared to longer-term feeding. Another notable difference of the short-term feeding response was the alteration of genes relating to components of the insulinlike growth factor signalling pathway that is implicated in a number of chronic diseases ${ }^{(21)}$. This report provides strong rationale for assessing the response to $7 \mathrm{~d}$ of bean consumption and for evaluating rat hepatic stress and toxicity genes with increasing bean dose intake in rats. To our knowledge, no studies have examined dose-dependent acute effects of increased cooked bean consumption, such that findings may inform the safety profile of acute hepatic responses to increased bean consumption in humans.

Dry bean intake was designed to encompass levels of consumption occurring in human populations worldwide ${ }^{(1)}$. As recently reported ${ }^{(2)}$, intake in the United States tends to be very low and current information indicates that only $17 \%$ of individuals in the United States consume dry bean on any given day; whereas in parts of Africa, consumption is estimated to be as high as $40 \mathrm{~kg} /$ capita per year. The inclusion of $60 \% \mathrm{w} / \mathrm{w}$ dry bean in the experimental design, which represents an amount equivalent to approximately $1104 \mathrm{~g}$ cooked bean/d in the human diet, greatly exceeds the amount of bean consumed by any known population and created a robust opportunity to inspect the animals' response for evidence of stress induction or toxicity.

\section{Genes significantly affected by bean dose}

Ccng1, also referred to as Cyclin $\mathrm{G}_{1}$, is a protein involved in the $\mathrm{G}_{2} / \mathrm{M}$ checkpoint as a downstream mediator of the p53 pathway ${ }^{(37)}$. The gene expression of Ccng1 did not increase in a linear fashion in response to increased red bean in the diet, but instead, the expression peaked at $7.5 \%$ bean and was significantly decreased compared to control at $60 \%$ bean, consistent with a nonlinear dose-response (Fig. 2(a)). However, if the p53 pathway was meaningfully affected by the dry bean diet, it would be expected that other proteins in the p53 pathway proteins would have been affected as well $^{(38)}$. Here, four other genes in the p53 pathway, Bcl2associated $\mathrm{X}$ protein (Bax), caspase 8 (Casp8), growth arrest and DNA-damage-inducible, $45 \alpha$ (Gadd45a) and p53 binding protein homologue $(M d m 2)$, were included in this analysis; however, they did not display significant expression changes in response to dry bean dose.

Cyp3a11 is a member of the CYP3 family of cytochrome p450 proteins. This phase I enzyme metabolises many exogenous compounds including prescription drugs, as well as endogenous substrates such as steroids and bile acids $^{(39)}$. A marked, significant increase in Cyp3a11 expression was only detected in the $60 \%$ red bean diet when compared to lower doses and control (Fig. 2(b)) Further examination of red bean consumption effects would be of interest in order to determine which bean components were responsible for an effect on this phase I drug metabolising enzyme.

Fmo1 is a member of the flavin mono-oxygenase family that catalyses the oxygenation of a broad range of substrates including nucleophilic nitrogen, sulphur, phosphorus and other heteroatom-containing xenobiotics, chemicals and drugs ${ }^{(40,41)}$. Fmo1 is primarily expressed by the liver; however, species-specific differences have been noted, such that less Fmo1 is expressed by adult human liver compared to rat ${ }^{(40)}$. Fmo1 expression was significantly increased in response to the $60 \%$ red bean diet (Fig. 2(c)). It is possible that bean components in the red bean diet are responsible for directly or indirectly inducing expression of this gene family as part of a normal metabolic process.

Gstm1 is an isoform of glutathione $S$-transferase. These transferases are involved in the detoxification of a wide variety of chemicals. Gstm 1 is a hepatic glutathione $S$-transferase, and has been found to have an antioxidant response element 
(a)

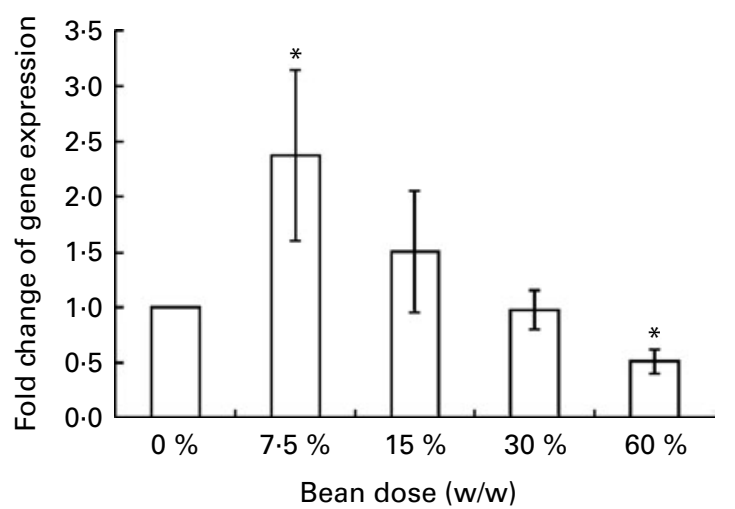

(c)

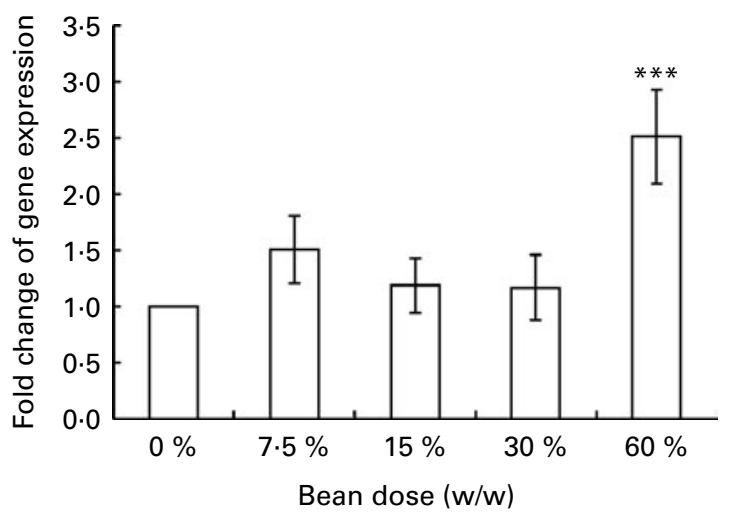

(e)

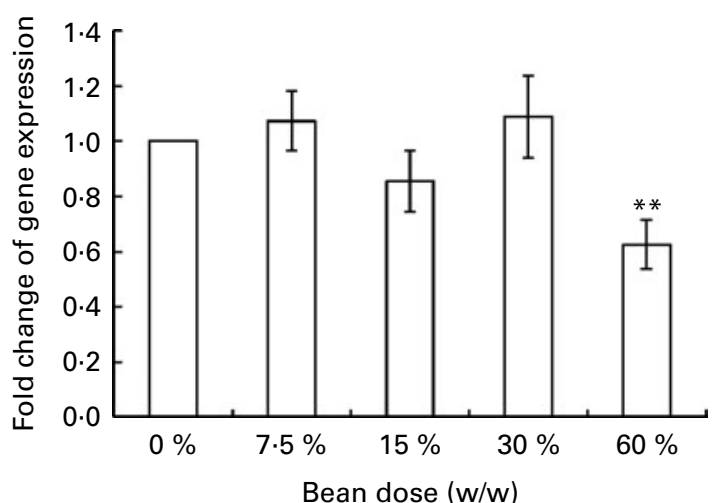

(b)

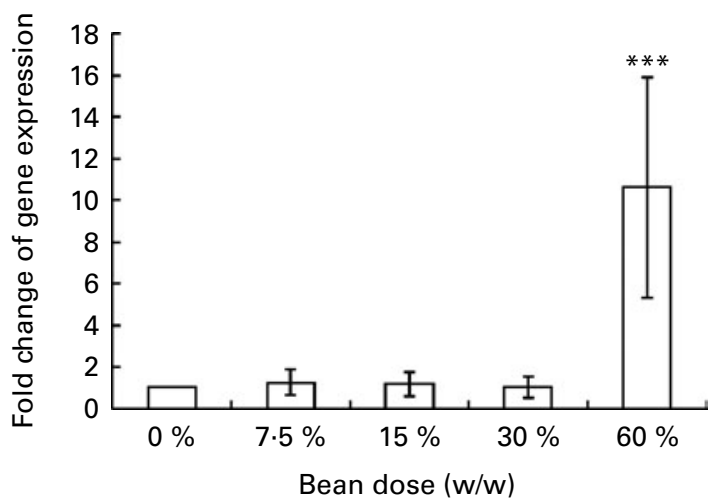

(d)

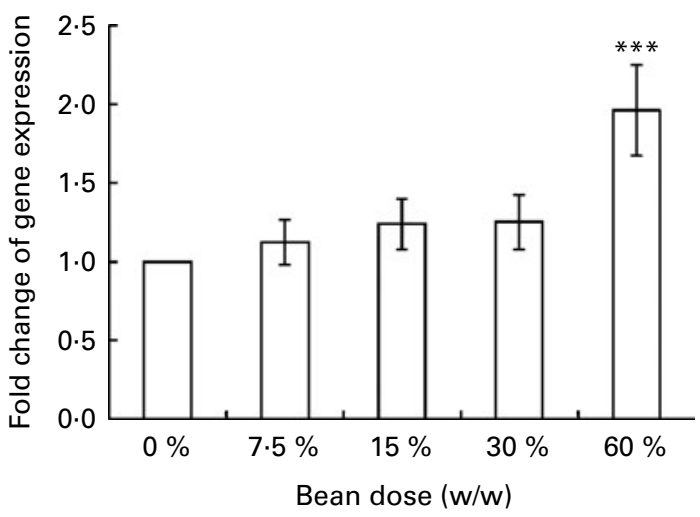

(f)

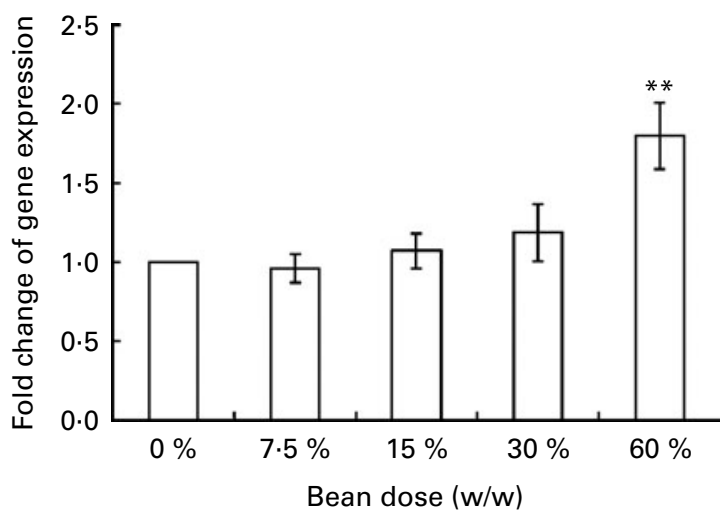

Fig. 2. Dietary bean dose-dependent changes in hepatic gene expression. Fold change refers to gene expression after $7 \mathrm{~d}$ of feeding a bean diet containing 7.5 , 15,30 or $60 \% \mathrm{w} / \mathrm{w}$ compared with expression from consumption of $0 \%$ bean as measured by quantitative real-time PCR (w/w is equal to the mass of bean powder in $\mathrm{g} / 100 \mathrm{~g}$ of total diet). Fold changes for each of the six transcripts significantly affected by bean diet are provided for each bean dose group. (a) Cyclin G1 (Ccng1); (b) cytochrome p450 3a1 (Cyp3a11); (c) flavin containing mono-oxygenase 1 (Fmo1); (d) glutathione S-transferase mu1 (Gstm1); (e) heat shock protein 8 (Hspa8); (f) macrophage migration inhibitory factor (Mif). Dunnett's post hoc analysis was performed to individually compare each dosage group to the control $(0 \%)$, and those that were found to be significantly different are marked with: ${ }^{\star} P<0.05,{ }^{\star \star} P<0.01,{ }^{\star \star \star} P<0.001$.

within the promoter region ${ }^{(42)}$. Slight induction was detected in animals fed the lower bean doses with significantly increased Gstm1 expression observed at $60 \% \mathrm{w} / \mathrm{w}$ red bean consumption (Fig. 2(d)). The antioxidant content of small red bean used in this study was recently reported ${ }^{(16)}$; and taken together, these findings suggest that the role of this chemical class of compounds from beans be further examined as possible triggers for rat liver Gstm1 induction.
Hspa8 encodes for HSC70, a member of the $70 \mathrm{kDa}$ heat shock protein family. Heat shock proteins, also known as chaperones, assist with protein synthesis, repair and degradation. They are induced in response to improperly folded proteins, and thus their up-regulation is sometimes measured as an indicator of cellular stress ${ }^{(43)}$. HSC70 is constitutively expressed and involved in many housekeeping chaperone functions ${ }^{(44)}$. Overall, eleven genes were analysed that are 
(a)

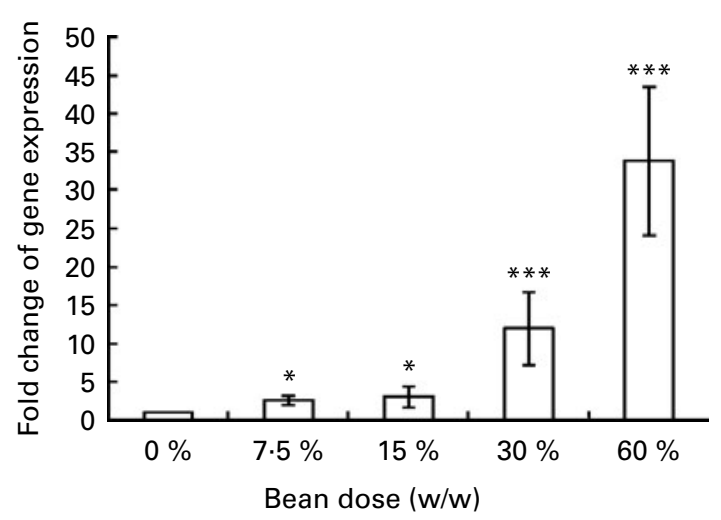

(b)

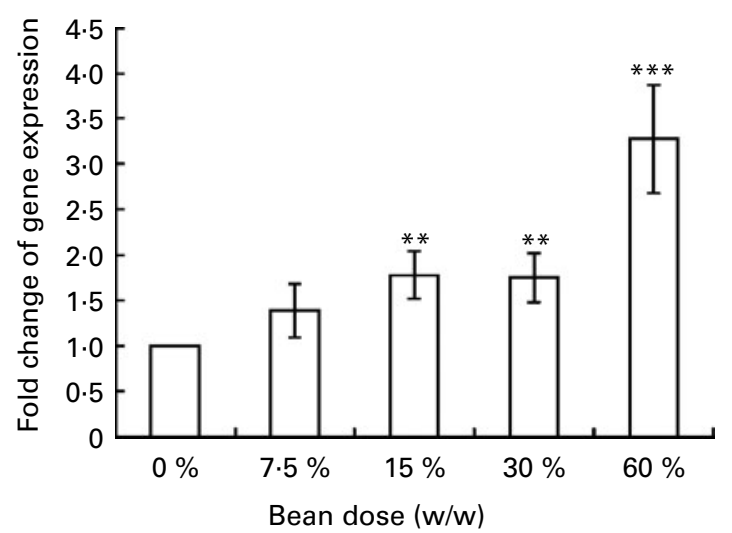

Fig. 3. Dietary bean intake induced gene expression of hepatic cytochrome p450 7a1 (Cyp7a1) and UDP glycosyltransferase 1 (Ugt1a6) family polypeptide A6. (a) Cyp7a1; (b) Ugt1a6. Fold change refers to gene expression after $7 \mathrm{~d}$ of feeding a bean diet containing $7.5,15,30$ or $60 \%$ w/w compared with expression from consumption of $0 \%$ bean as measured by quantitative real-time PCR (w/w is equal to the mass of bean powder in $\mathrm{g} / 100 \mathrm{~g}$ of total diet). Dunnett's post hoc analysis was performed to individually compare each dosage group to the control $(0 \%)$, and those that were found to be significantly different are marked with: ${ }^{\star} P<0.05,{ }^{* \star} P<0.01,{ }^{* \star *} P<0.001$.

involved in heat shock response pathways, and Hspas was the only affected gene. Expression of Hspas was decreased at the $60 \% \mathrm{w} / \mathrm{w}$ bean dose (Fig. 2(e)). Given that Hspas expression was reduced in response to increased bean consumption, contrary to what would be expected for cellular stress, these findings suggest that dry bean consumption did not alter heat shock protein expression in a manner indicative of a stress response in the liver.

Mif is a macrophage migration inhibitory factor, and is a pro-inflammatory cytokine mainly produced by macrophages and monocytes ${ }^{(45)}$. Mif expression can be altered by exposure to pathogens ${ }^{(46)}$ but may also be affected by inflammation, neuroendocrine mechanisms and glucocorticoids ${ }^{(47)}$. While changes in Mif expression have not been thoroughly investigated in response to diet or bioactive food components, Mif expression was significantly up-regulated in liver at the $60 \%$ $\mathrm{w} / \mathrm{w}$ bean dose compared to control (Fig. 2(f)). A total of thirteen genes involved in inflammatory pathways were included in this array, and Mif was the only one in this group that demonstrated a significant change following bean consumption. Dry bean modulation of Mif expression alone did not reveal a role for beans in the initiation of a pro-inflammatory response.

\section{Candidate genes for disease prevention by beans}

Ugt1a6 is a UDP-glucuronosyltransferease (UGT) proteinencoding gene. These conjugative enzymes mediate phase II detoxification reactions as they are responsible for conjugation of the glucuronic acid group of uridine diphosphoglucuronic acid to the functional group of a wide range of substrates ${ }^{(48)}$. Fig. 3(a) shows that Ugt1a6 expression was up-regulated in a dose-dependent manner by dry bean consumption, with noteworthy induction at 7.5\% (1.5-fold), 15\% (2-fold), 30\% (2-fold) and 60\% (3-fold) w/w dry bean when compared to control. Increased Ugt1a6 expression by beans may exert cancer preventive effects in the liver of humans by facilitating the metabolism of environmental carcinogens.
Conjugation with a glucuronic acid moiety increases the solubility of its substrate, and facilitates excretion into bile or urine. Substrates for UGT enzymes include endogenous compounds such as biliary acids, steroid hormones, bilirubin, retinoic acids and fatty acids, as well as exogenous compounds including carcinogens, drugs, environmental toxicants and dietary constituents ${ }^{(49)}$. Expression of the UGT1 class of enzymes is regulated via a positive feedback mechanism, such that concentrations of a particular substrate can elicit expression of the specific UGT1 isoenzyme responsible for that substrate's modification/detoxification. Thus, an increase in the concentration of a single substrate for Ugt1a 6 from dietary bean intake may be the reason for further up-regulation of Ugt1a6 observed at higher doses of bean consumption. As a result of up-regulating the Ugt1a6 enzyme, glucuronidation reactions increase, facilitating removal of carcinogens or environmental toxins from the body. Induction of phase II enzymes such as UGT are considered a major mechanism by which phytochemicals become active for cancer preven$\operatorname{tion}^{(48,50)}$, and is identified from this study as a target pathway that merits further investigation following increased consumption of beans in humans.

Cyp7a1 encodes for cytochrome p450 7A1, which has also been reported as cholesterol $7 \alpha$ hydoxylase or cholesterol $7 \alpha$-mono-oxygenase. Increased expression of Cyp $7 a 1$ may promote cholesterol saturation of bile and increased excretion of cholesterol from the body ${ }^{(51,52)}$ and thus can result in lowered serum levels of cholesterol. Fig. 3(b) shows that Cyp $7 a 1$ expression increased with dietary dry bean consumption in a dose-dependent manner, with the greatest induction detected at $60 \% \mathrm{w} / \mathrm{w}$. Multiple diet intervention studies have demonstrated plasma cholesterol-lowering effects of a bean-containing diet ${ }^{(6-8,53-56)}$. The mechanisms responsible for decreased serum cholesterol levels are not fully elucidated, even though this is the most consistently observed health benefit correlated with dry bean consumption. To our knowledge, these data are the first to demonstrate that induction of liver cyp $7 a 1$ expression by dietary bean intake may be a mechanism by 
which increased bean consumption is protective against heart disease. These findings merit further investigation of inducible cyp $7 a 1$ expression as a mechanism for cholesterol-reducing effects in humans.

\section{Concluding remarks}

The absence of major changes in growth rate or hepatic expression of stress and toxicity-related genes following increased dietary intake of cooked dry beans indicated that adverse effects are unlikely to occur when consumed at elevated daily doses that promote chronic disease prevention. This conclusion is based on patterns of expression for eighty-four genes involved in stress and toxicity pathways. Overall, six genes were identified from the present study that were up- or down-regulated relative to the control group, and only when the concentration of bean greatly exceeded typical consumption (e.g. $30 \%$ or $60 \% \mathrm{w} / \mathrm{w}$ ).

In this study, two of the eighty-four genes, Cyp7a1 and Ugt1a6, were up-regulated with a linear response to increasing bean dose. The Cyp $7 a 1$ and Ugt1a6 gene pathways are novel target pathways that merit further investigation following bean consumption in humans due to their association with disease prevention. These data imply that high doses of dry bean consumption can be safely tested in human intervention trials to evaluate therapeutic and chronic disease preventive properties. While epidemiological studies have shown positive associations between dry bean consumption and reduced risk for cancer and heart attack; prospective, randomised and placebo-controlled clinical intervention trials are required to critically evaluate these relationships, and such studies need to consider the full range of dietary intakes that typify the world's populations, albeit within safe and achievable limits. In order to fully realise the potential for beans' health benefits, an experimental design that will examine amounts up to $600 \mathrm{~g}$ of cooked dry bean intake/d may be necessary for humans. Studies of increased bean consumption in human subjects should still include standard toxicity profiling of blood components and serum analytes, particularly for participants with chronic disease. There may be a number of barriers to increased bean consumption, e.g. perceived gastrointestinal discomfort, lack of knowledge about preparation methods, and perceptions that dry bean is 'poor man's food', that may limit the amount of dry bean that people will consume on a daily basis. However, this study demonstrates that the potential for stress, inflammatory or toxic responses at doses that may exhibit disease prevention activity is unlikely to be a major concern.

\section{Acknowledgements}

The present study was supported in part by USAID Grant No. REE-A-00-03-00094-00, the Bean Health Alliance, and United States Department of Agriculture National Institute of Food and Agricultural Agriculture and Food Research Initiative Project No.: 2009-01929. The authors thank John McGinley and Elizabeth Neil for their excellent technical assistance. E. L. D. conducted the rodent feeding, assessment of gene expression and data analyses. E. P. R. and M. A. B. participated in various aspects of study implementation and data evaluation and interpretation. H. J. T. designed the feeding study and provided oversight on all aspects of the experiment. All authors participated in the writing of the manuscript. The authors declare that there are no conflicts of interest in relation to this study.

\section{References}

1. Faostat \& FAO (2009) http://faostat.fao.org

2. Mitchell DC, Lawrence FR, Hartman TJ, et al. (2009) Consumption of dry beans, peas, and lentils could improve diet quality in the US population. J Am Diet Assoc 109, 909-913.

3. Geil PB \& Anderson JW (1994) Nutrition and health implications of dry beans: a review. J Am Coll Nutr 13, 549-558.

4. Bennink MR \& Rondini EA (2008) Beans and Health: A Comprehensive Review. http://beaninstitute.com/wp-content/ uploads/2010/01/Bennink-and-Rondini-article.pdf

5. Van Cleave J, Gortmaker SL \& Perrin JM (2010) Dynamics of obesity and chronic health conditions among children and youth. JAMA 303, 623-630.

6. Anderson JW \& Gustafson NJ (1988) Hypocholesterolemic effects of oat and bean products. Am J Clin Nutr 48, 749-753.

7. Finley JW, Burrell JB \& Reeves PG (2007) Pinto bean consumption changes SCFA profiles in fecal fermentations, bacterial populations of the lower bowel, and lipid profiles in blood of humans. J Nutr 137, 2391-2398.

8. Winham DM, Hutchins AM \& Johnston CS (2007) Pinto bean consumption reduces biomarkers for heart disease risk. J Am Coll Nutr 26, 243-249.

9. Kabagambe EK, Baylin A, Ruiz-Narvarez E, et al. (2005) Decreased consumption of dried mature beans is positively associated with urbanization and nonfatal acute myocardial infarction. J Nutr 135, 1770-1775.

10. Adebamowo CA, Cho E, Sampson L, et al. (2005) Dietary flavonols and flavonol-rich foods intake and the risk of breast cancer. Int J Cancer 114, 628-633.

11. Lanza E, Hartman TJ, Albert PS, et al. (2006) High dry bean intake and reduced risk of advanced colorectal adenoma recurrence among participants in the polyp prevention trial. J Nutr 136, 1896-1903.

12. Aune D, De Stefani E, Ronco A, et al. (2009) Legume intake and the risk of cancer: a multisite case-control study in Uruguay. Cancer Causes Control 20, 1605-1615.

13. Southon IW. (1994) Phytochemical Dictionary of the Leguminosae. London: Chapman \& Hall.

14. Carbonaro M, Grant G, Cappelloni M, et al. (2000) Perspectives into factors limiting in vivo digestion of legume proteins: antinutritional compounds or storage proteins? J Agric Food Chem 48, 742-749.

15. Lajolo FM \& Genovese MI (2002) Nutritional significance of lectins and enzyme inhibitors from legumes. J Agric Food Chem 50, 6592-6598.

16. Thompson MD, Brick MA, McGinley JN, et al. (2009) Chemical composition and cancer inhibitory activity of dry bean market classes. Crop Sci 49, 179-186.

17. Pusztai A, Clarke EM \& King TP (1979) The nutritional toxicity of Phaseolus vulgaris lectins. Proc Nutr Soc 38, $115-120$.

18. Nasi A, Picariello G \& Ferranti P (2009) Proteomic approaches to study structure, functions and toxicity of 
legume seeds lectins. Perspectives for the assessment of food quality and safety. J Proteomics 72, 527-538.

19. Rodhouse JC, Haugh CA, Roberts D, et al. (1990) Red kidney bean poisoning in the UK: an analysis of 50 suspected incidents between 1976 and 1989. Epidemiol Infect 105, 485-491.

20. Jaffe WG \& Lette CL (1968) Heat-labile growth-inhibiting factors in beans (Phaseolus vulgaris). J Nutr 94, 203-210.

21. Narasaka S, Endo Y, Fu Z, et al. (2006) Safety evaluation of hypoallergenic wheat flour by using a DNA microarray. Biosci Biotechnol Biochem 70, 1464-1470.

22. Reeves PG, Nielsen FH \& Fahey GC Jr (1993) AIN-93 purified diets for laboratory rodents: final report of the American Institute of Nutrition ad boc writing committee on the reformulation of the AIN-76A rodent diet. J Nutr 123, 1939-1951.

23. Thompson MD, Thompson HJ, Brick MA, et al. (2008) Mechanisms associated with dose-dependent inhibition of rat mammary carcinogenesis by dry bean (Phaseolus vulgaris L.). J Nutr 138, 2091-2097.

24. Wu X, Gu L, Prior RL, et al. (2004) Characterization of anthocyanins and proanthocyanidins in some cultivars of Ribes, Aronia, and Sambucus and their antioxidant capacity. J Agric Food Chem 52, 7846-7856.

25. Livak KJ \& Schmittgen TD (2001) Analysis of relative gene expression data using real-time quantitative PCR and the 2(-Delta Delta C(T)) method. Methods 25, 402-408.

26. Benjamini Y \& Hochberg Y (1995) Controlling the false discovery rate: a practical and powerful approach to multiple testing. J R Statist Soc B 57, 289-300.

27. Crampton EW, Farmer FA, Mc KH, et al. (1960) A statistical study of apparent digestibility coefficients of the energyyielding components of nutritionally adequate mixed diet consumed by 103 young human adults. J Nutr 72, 177-184.

28. Farrell DJ, Girle L \& Arthur J (1978) Effects of dietary fibre on the apparent digestibility of major food components and on blood lipids in men. Aust J Exp Biol Med Sci 56, 469-479.

29. Kelsay JL, Behall KM \& Prather ES (1978) Effect of fiber from fruits and vegetables on metabolic responses of human subjects I. Bowel transit time, number of defecations, fecal weight, urinary excretions of energy and nitrogen and apparent digestibilities of energy, nitrogen, and fat. Am J Clin Nutr 31, 1149-1153.

30. Kelsay JL, Goering HK, Behall KM, et al. (1981) Effect of fiber from fruits and vegetables on metabolic responses of human subjects: fiber intakes, fecal excretions, and apparent digestibilities. Am J Clin Nutr 34, 1849-1852.

31. Bressani R \& Elias LG (1984) Relation between the digestibility and protein value of the common bean (Phaseolus vulgaris). Arch Latinoam Nutr 34, 189-197.

32. Bressani R, Hernandez E \& Braham JE (1988) Relationship between content and intake of bean polyphenolics and protein digestibility in humans. Plant Foods Hum Nutr 38, 5-21.

33. Njintang NY, Mbofung CM \& Waldron KW (2001) In vitro protein digestibility and physicochemical properties of dry red bean (Phaseolus vulgaris) flour: effect of processing and incorporation of soybean and cowpea flour. J Agric Food Chem 49, 2465-2471.

34. Viquez Rodriguez F \& Bonilla Leiva AR (2002) Effect of pectinase and cellulase addition on in vitro digestibility of common bean (Phaseolus vulgaris). Arch Latinoam Nutr 52, 151-154.

35. Admassu Shimelis E \& Kumar Rakshit S (2005) Antinutritional factors and in vitro protein digestibility of improved haricot bean (Phaseolus vulgaris L.) varieties grown in Ethiopia. Int J Food Sci Nutr 56, 377-387.
36. Costa de Oliveira A \& Sgarbieri VC (1986) Effect of diets containing dry beans (Phaseolus vulgaris L.) on the rat excretion of endogenous nitrogen. $J$ Nutr 116, 2387-2392.

37. Kimura SH, Ikawa M, Ito A, et al. (2001) Cyclin G1 is involved in $\mathrm{G} 2 / \mathrm{M}$ arrest in response to DNA damage and in growth control after damage recovery. Oncogene 20, 3290-3300.

38. Levine AJ, Hu W \& Feng Z (2006) The P53 pathway: what questions remain to be explored? Cell Death Differ 13, 1027-1036.

39. Nebert DW \& Russell DW (2002) Clinical importance of the cytochromes P450. Lancet 360, 1155-1162.

40. Cashman JR (1995) Structural and catalytic properties of the mammalian flavin-containing monooxygenase. Chem Res Toxicol 8, 166-181.

41. Krueger SK \& Williams DE (2005) Mammalian flavincontaining monooxygenases: structure/function, genetic polymorphisms and role in drug metabolism. Pharmacol Ther 106, 357-387.

42. Hayes JD, Flanagan JU \& Jowsey IR (2005) Glutathione transferases. Annu Rev Pharmacol Toxicol 45, 51-88.

43. Rokutan K, Hirakawa T, Teshima S, et al. (1998) Implications of heat shock/stress proteins for medicine and disease. J Med Invest 44, 137-147.

44. Daugaard M, Rohde M \& Jaattela M (2007) The heat shock protein 70 family: Highly homologous proteins with overlapping and distinct functions. FEBS Lett 581, 3702-3710.

45. Paralkar V \& Wistow G (1994) Cloning the human gene for macrophage migration inhibitory factor (MIF). Genomics 19, 48-51.

46. Bacher M, Meinhardt A, Lan HY, et al. (1997) Migration inhibitory factor expression in experimentally induced endotoxemia. Am J Pathol 150, 235-246.

47. Donn RP \& Ray DW (2004) Macrophage migration inhibitory factor: molecular, cellular and genetic aspects of a key neuroendocrine molecule. J Endocrinol 182, 1-9.

48. Iyanagi T (2007) Molecular mechanism of phase I and phase II drug-metabolizing enzymes: implications for detoxification. Int Rev Cytol 260, 35-112.

49. Guillemette C (2003) Pharmacogenomics of human UDP-glucuronosyltransferase enzymes. Pharmacogenomics J 3, 136-158.

50. Nagar S \& Remmel RP (2006) Uridine diphosphoglucuronosyltransferase pharmacogenetics and cancer. Oncogene 25, 1659-1672.

51. Lehmann JM, Kliewer SA, Moore LB, et al. (1997) Activation of the nuclear receptor LXR by oxysterols defines a new hormone response pathway. J Biol Chem 272, 3137-3140.

52. Lu TT, Repa JJ \& Mangelsdorf DJ (2001) Orphan nuclear receptors as eLiXiRs and FiXeRs of sterol metabolism. J Biol Chem 276, 37735-37738.

53. Nervi F, Covarrubias C, Bravo P, et al. (1989) Influence of legume intake on biliary lipids and cholesterol saturation in young Chilean men. Identification of a dietary risk factor for cholesterol gallstone formation in a highly prevalent area. Gastroenterology 96, 825-830.

54. Rigotti A, Marzolo MP, Ulloa N, et al. (1989) Effect of bean intake on biliary lipid secretion and on hepatic cholesterol metabolism in the rat. J Lipid Res 30, 1041-1048.

55. Duane WC (1997) Effects of legume consumption on serum cholesterol, biliary lipids, and sterol metabolism in humans. J Lipid Res 38, 1120-1128.

56. Birketvedt GS, Travis A, Langbakk B, et al. (2002) Dietary supplementation with bean extract improves lipid profile in overweight and obese subjects. Nutrition 18, 729-733. 